August 20, 2020

\title{
The Evolutionary Psychology of Conflict and the Functions of Falsehood
}

\author{
Michael Bang Petersen ${ }^{1 *}$ \\ Mathias Osmundsen ${ }^{1}$ \\ John Tooby ${ }^{2}$
}

\begin{abstract}
${ }^{1}$ Department of Political Science, Aarhus University, Denmark
${ }^{2}$ Center for Evolutionary Psychology, University of California, Santa Barbara, USA

*Corresponding author: michael@ps.au.dk
\end{abstract}

\begin{abstract}
Truth is commonly viewed as the first casualty of war. As such the current circulation of fake news, conspiracy theories and other hostile political rumors is not a unique phenomenon but merely another example of how people are motivated to dispend with truth in situations of conflict. In this chapter, we theorize about the potentially evolved roots of this motivation and outline the structure of the underlying psychology. Specifically, we focus on how the occurrence of intergroup conflict throughout human evolutionary history has built psychological motivations into the human mind to spread information that (a) mobilize the ingroup against the outgroup, (b) facilitate the coordination of attention within the group and (c) signal commitment to the group to fellow ingroup members. In all these instances, we argue, human psychology is designed to select information that accomplishes these goals most efficiently rather than to select information on the basis of its veracity. Accordingly, we hypothesize that humans in specific instances are psychologically prepared to prioritize misinformation over truth.
\end{abstract}

Book chapter prepared for inclusion in The Politics of Truth in Polarized America Concepts, Causes and Correctives, edited by David C. Barker and Elizabeth Suhay, Oxford University Press. 
For as long as people have analyzed politics, they have been worried about whether demagogues and propaganda manipulate the public into entertaining false beliefs about the world. Historically, some of the most murderous political programs such as the genocides of the National Socialists, the Hutu extremists in Rwanda, and the ethnic cleansings in Ex-Yugoslavia have all been explained with reference to the circulation of falsehoods by political entrepreneurs. Today, with the advent of the Internet, concerns have emerged that falsehoods have become a routine part of the daily news diet of ordinary citizens in advanced democracies. Thus, across the social sciences and in elite political discourse, there is an increasing focus on "fake news," conspiracy theories and other forms of lowevidence information, which portray politicians and political groups in negative ways. Indeed, history past and present suggests that the propagation of socially mobilizing beliefs that are markedly divorced from reality are an endemic feature of stratified societies, and perhaps of all societies. In relation to current politics, studies demonstrate that citizens not only participate themselves in the spread of false information on social media (Vosoughi et al., 2018), they also tend to believe false information. This is especially the case if the information is aligned with people's own political allegiances. Currently in the United States, for example, large numbers of supporters of the Democratic and Republican parties indicate their belief in conspiracy theories that portray the opposing party in a negative way (Miller et al., 2016). Similar results have been found in other countries such as Denmark (Osmundsen \& Petersen, 2019).

A popular explanation for beliefs in low-evidence information, including information that is obviously false or highly unlikely to be valid, is ignorance (e.g., Pennycook \& Rand, 2019). In this perspective, people are motivated to hold accurate beliefs but are not motivated enough to invest effort in sorting out the true from the false. Such an explanation fits a narrative of a politically incompetent citizenry, a narrative that has been promoted in political science for decades. 
In this chapter, we outline and promote a different view. Specifically, we question the core underlying assumption of the ignorance perspective: that humans should be solely motivated to pursue accurate beliefs. This would only be true if the sole function of adopting and holding beliefs was to guide behavior so that it meshed with the way things actually are. Indeed, if the beliefs are false then behavior based on their being true will (usually) be unsuccessful, sometimes catastrophically so. In contrast, we argue that the generation, adoption, and propagation of beliefs evolved to serve many other functions. Some of these functions are best served by creating, adopting, or spreading inaccurate or false information - and all too frequently, the truth of a belief is just not relevant for its purposes.

In political science and psychology, such a view is often referred to as an example of "directional motivated reasoning", which exactly emphasizes that reasoning and, hence, belief formation is motivated by particular directional goals beyond accuracy (Taber \& Lodge, 2006). Often such motivated reasoning is explained with reference to social identity theory, the need to belong, or the need to uphold positive images (e.g., Huddy \& Bankert, 2017). Such needs can ostensibly induce people to falsely believe that their group is better than it really is, simply to avoid facing the hurtful truth.

While many of our proposals are aligned with a motivated reasoning perspective, we seek to provide an explanation at a different and deeper level. Specifically, we ask: What are the functions of the psychological mechanisms that motivate us to hold and share false information? In general, when we say false, we mean that as a shorthand that includes beliefs and information unfiltered for its truth value, coherence, or deceptiveness; or like value judgments, are inherently incapable of either being true or false.

In answering this question, we apply a theoretical framework developed specifically to develop hypotheses by considering the role of function in the organization of the human mind: 
Evolutionary psychology (Tooby \& Cosmides, 1992). The approach of evolutionary psychological can be illuminated by considering a simpler example: "Why do people eat?" Most political and social psychological theories (e.g., social identity theory) focus on psychological needs and, hence, would answer that people eat in order to avoid feeling hungry. Evolutionary psychology, in contrast, is based on the recognition that psychological mechanisms were introduced into our evolved neural architecture by natural selection, and did so because their operation caused our ancestors to gain tangible, adaptive benefits. Indeed, like a key fitting a lock, the specific organization of the mechanism's functional design (the shape of the key) can be traced to how they solved their adaptive problem (discharged their function) given the structure of the ancestral world (the shape of the lock). The hunger motivational system led humans to cost-effectively seek and eat the best array of foods with the highest payoffs in calories and nutrients, and the lowest toxin loads. So, here we ask: What tangible adaptive benefits can there be to selecting, fabricating, or sharing false information and holding false beliefs? Our goal is thus theoretical. We apply evolutionary psychology as a tool for the development of testable hypotheses about the psychology underlying falsehoods. Given this focus, we do not seek to offer firm empirical evidence that these hypotheses are true nor that the hypothesized psychology is, in fact, the product of natural selection. As such, we sidestep many important questions about how cultural evolutionary and developmental processes will interact with the products of natural selection, as will always be the case (see Richerson et al. [2016] and associated commentaries).

Evolutionary psychology is an approach that allows researchers to dissect how natural selection has given our minds an array of distinct psychological mechanisms, each designed for solving a different adaptive problem. Evolutionary psychology is based on the combination of two insights: The first insight comes from evolutionary biology, and is the recognition that there is no other (natural) explanation for how organisms acquired their functional biological machinery (e.g., 
color vision, sexual attraction, photosynthesis, wings) than evolution by natural selection (Williams, 1966). The second insight comes from modern cognitive psychology, and is the recognition that the human mind is a collection of mechanisms, the great majority of which (or all) have specialized adaptive functions, like apps on a smart phone (Kurzban, 2012). These include not only functionally specialized adaptations for eating and mating, but also for functions relevant to political scientists, such as coalition formation and management, cooperation, aggression, dominance and subordination in hierarchies, inferring the intentions and values of groups, leadership and followership, and group mobilization (Buss, 2015; Petersen, 2015a; Tooby \& Cosmides, 2010). Our goal in this chapter is not to review this approach, but to use it to illuminate, if we can, the issue of the functional role of false information in political phenomena. We will simply refer the reader to existing introductions to this paradigm (Buss, 2015), some of which have been explicitly tailored to political scientists (Petersen, 2015b).

What will be important in the following, however, is the added insight that natural selection is a slow and backward-looking process. Because the rise of agriculture has been too recent and rapid, the evolved psychology of modern humans is designed for the demands of our forager ancestors living in past environments (Diamond, 2013). One of the key problems that our ancestors faced was conflict and, in particular, group-based conflict, including factional conflict (Tooby, Cosmides \& Price, 2006; Tooby \& Cosmides, 2010). Our particular focus in this chapter is to theorize how the existence of group-based conflict has selected for psychological mechanisms that are functionally designed to propagate false beliefs. To understand why, we need to understand the selection pressures that operate on organisms involved in conflict. To introduce this, we will begin by considering conflict between non-human animals. From this starting point, we expand the discussion to include human group-based conflict and how the circulation of falsehoods may have increased our ancestors' likelihood of prevailing in group-based conflict. 


\section{Conflict Among Non-Human Animals}

The behavior of animals in conflict situations are one of the most well-studied topics within the animal behavior literature. The canonical model is the asymmetric war of attrition (Sell et al 2009; Huntingford, 2013). This model captures situations of overt conflict such as, for example, when two animals meet in the open to determine access to territories or mating partners. According to this model, animals in conflict are building a prediction model about who would win if the conflict escalated into a physical fight and carried on to completion. For each contestant, it is better to withdraw early if loss is inevitable, because they save the costs they would otherwise have expended, and the outcome-loss - is the same in both cases. Often adversaries will conform their behavior automatically to their ability to inflict costs (formidability), which determines their bargaining power. Overt conflict among animals therefore has often taken on a ritualistic appearance where animals are generating (and, as we will see, manipulating) perceptions of each other's fighting ability to "win"in the sense of persuading their opponent to yield.

For animals of the same species (and, hence, the same natural weaponry such as fangs, claws and tusks), the best predictor of relative fighting ability are relative differences in physical size and physical strength. Natural selection has accordingly built mechanisms into the minds of animals, which are activated when facing a contestant, designed to attend to any cues that are reliably associated with these differences (Arnott \& Elwood, 2009). For example, male deer facing each other at a distance start out with roaring, with the loudness being correlated with the physical size. This is a noisy cue and, hence, if no clear predictions can be made about who is larger and stronger, the contest proceeds to its next level: Parallel walking. The two male deer walk next to each other, back and forth, to directly visually inspect the size of their opponents from the angle in which information can be most reliably extracted about size: The side. The key thing here is that this is not just a 
ritualized exercise to prepare for the real fight. Instead it is an attempt to win by causing the assessment system in the opponent to conclude that they would lose if they proceeded. If it is clear that one animal will lose, the adaptive response is to withdraw. Only if parallel-walking does not generate a reliably clear enough prediction does the next and final level ensue: The locking of anglers in direct combat. Such combat is costly and can involve severe wounds. It is therefore better to avoid it, if possible.

Accuracy is obviously important here. The adaptive target of the evolved psychological systems is to ensure that organisms do not end up in a fight with a stronger opponent. Yet, a subtle distinction is important here to understand the exact role of accuracy: the distinction between cues and signals. Cues are something that the receiver extracts. A signal is something that the sender emits. In conflict, it is important for the receiver to extract extremely accurate cues about fighting ability. For the signaler, in contrast, there are adaptive benefits to emitting signals that exaggerate the signaler's fighting ability. The functional product of this adaptive system is to increase the probability the adversary's assessment system will misperceive the signaler's formidability as greater than it is. This will cause the opponent to withdraw from a fight they otherwise might have won. Hence, in conflict, natural selection favors mechanisms designed to instill false representations in the mind of one's opponents.

This dynamic unleashed a coevolutionary race (Dawkins \& Krebs, 1978). Selection creates adaptations to reliably assess the formidability of opponents on the basis of the cues they emit (e.g., size). These assessment systems, and the cues they evolve to register, then select in their adversaries for modifications that in appearance and behavior mislead the assessment systems to overestimate formidability. These in turn select for discounting and the search for any remaining channels that still provide reliable information. There may be no stable outcome to this antagonistic coevolution, because any advantage on one side increases the selection for countervailing tactics 
(Tooby \& Cosmides, 2020). Manipulative signals should resemble the cues that the receiver relies on in the first place. One of the best studied examples is piloerection, where many species evolved to emit signals of an enlarged physical size (an otherwise valid cue) by raising the hair on their body (e.g., Muller \& Wrangham, 2004). The existence of this second-order selection pressure immediately creates third-order selection pressures whereby there are adaptive benefits for the receiver in being able to distinguish between honest and dishonest signals. Opponents need to be able to determine how much is inconsequential fur and how much is muscle. The evolution of conflict selects for manipulation, which breeds for evolution of vigilance.

In sum, animals thus habitually engage in manipulation of adversaries' representations situations involving conflicts of interests. It is important to recognize that the selection for deception is created by the prior existence of an assessment or communication system. This places constraints on manipulation as it evolved to operate within a previously well-functioning system. If manipulation becomes too widespread, and the assessment system fails too completely in executing its function, the organism will be selected to stop or downregulate attending to the signal.

What we will suggest in the following is at that these adversarial constraints are less likely to keep some forms of human falsehood production in check. This is because for some kinds of human signals, false signals are in the interest of both the sender and the receiver. The reason is that human conflicts often occur as between-group conflict and, therefore, involve intense withingroup cooperation as a precondition. For fellow group members preparing for conflict, signals of falsehoods are a cooperative rather than conflictual activity with the specific function of enhancing the group's likelihood of prevailing over other groups. Because they are cooperative, they are evolutionarily stable_-damping the system is disadvantageous. With conflict, turning down a deceptive signal is advantageous. 


\section{Human Group-Based Conflicts and the Selection of Coalitional Instincts}

Surprisingly, members of many species meet the world as if they were isolated atoms made from inert gases. They may aggregate spatially, but they seem unable to cognitively master the problems whose solution would allow them to combine into alliances and coalitions that could act jointly and advantageously. There are, for example, many situations when two or more strong individuals excluded by an alpha from reproduction could drive out the alpha and mate, if only they could ally with each other. But they seem to be unable to. In contrast, one of the zoologically unique features of humans is their ability to engage in ultra-complex cooperative activities with non-kin (Trivers, 1971; Tomasello, 2014; Tooby \& DeVore, 1987). This breakthrough in psychological adaptations supercharged the ability of humans to compete with each other collectively, by forming coalitions (teams, not aggregates). Once psychological adaptations evolve to support the capacity to form coalitions it propelled an evolutionary arms race for increasing the size, mobilization, coordination, and cohesion of coalitions. Thus, just as two can beat one, three can beat two, and so on. The dedicated coalitional programs this evolutionary history built unleashed group-mindedness on the human world. Now we infuse it into nearly everything humans do, from tribes and schools of art to soccer hooligans, religions and scientific movements. These evolved coalitional programs enable us and induce us to form, maintain, join, support, recognize, defend, defect from, factionalize, exploit, resist, subordinate, distrust, dislike, oppose, and attack coalitions (Petersen, 2015a; Pietraszewski et al., 2015; Tooby \& Cosmides, 2010; Tooby, Cosmides \& Price, 2006).

Coalitions in the sense intended here are sets of individuals interpreted by their members and/or by others as sharing a common abstract identity (including propensities to act as a unit, to defend joint interests, and to have shared mental states and other properties of a single human agent, such as status and prerogatives). Just as individuals, coalitions have status based on the magnitude of the benefits they can confer and the costs they can inflict (Sell, et al. 2009), and 
individual status is be partly a derived function of the status of the coalition she or he belongs to. Individuals will therefore exist in a symbiotic relationship with their coalitions. They are motivated to help the status of their coalition rise, and will feel increased entitlement to better treatment as it does. They will be motivated to fight any threat to the status of their coalition, but will feel lower entitlement if its status falls. This provides a functional account of the intuition (e.g., in social identity theory) that group attitudes serve the "function" of providing intangible feelings of self-esteem. From an evolutionary functional perspective, the assessments experienced as elevation, pride, shame, anger, and entitlement evolved to track real and material features about the relative values and behavioral options humans face when embedded in their social world. The sudden spread in the 1930s that the Germans were an ancient super-race responsible for all the advances of civilization, and were destined to rule was not just contagious because it made many Germans feel pleasure at the thought. Rather, it reflects part of a system for mutually promoting the actual social status of the group they belong to, in this case orienting them to-among other things-increased commitment to the social identity "German" (rather than, say, Catholic, or Social Democrat or Bavarian). Whether Germans are "great" is a subjective valuation incapable of being either true nor false; but this and related valuations were part of a system to guide coalitional action.

The primary payoff that selected for a psychology of alliance and coalition is the amplification of the power of a coalition's members in conflicts with non-members. Rival groups will attempt to expand at your expense; or will contract as a consequence of the growing dominance of your group. This amplification function explains a number of otherwise puzzling phenomena. For example, ancestrally, if you had no coalition you were nakedly at the mercy of everyone else who did. To have a coalition to stand with you was nearly as imperative as food or air. Hence, the instinct to belong to a coalition has psychological urgency, preexisting and superseding any policydriven basis for membership. The explicit content of a group's beliefs, as we will discuss, are often 
less important than the fact all group members hold the same beliefs and, in this way, that the beliefs signify a bounded set of individuals with mutual obligations towards each other. Coalitional programs evolved to promote the self-interest of the coalition's membership (in dominance, status, legitimacy, resources, moral force, etc.). This is why, from an evolutionary functional perspective, it is no surprise that even coalitions whose organizing ideology originates (ostensibly) to promote human welfare can slide into the most extreme forms of oppression, in complete contradiction to the putative values of the group.

In short, it bears emphasizing that although humans cooperate in groups for many purposes, group cooperation in the service of intergroup conflicts is arguably the most evolutionarily consequential domain. Thus, in contrast to many other species, human conflicts are seldom exclusively just one individual against another. Instead, human conflicts are group-based and — even if they start out as a one-on-one conflict—bystanders, friends, and kin often become entangled. In modern societies, group-based conflicts happen not just between a few individuals but can involve everything from friends, villages, ethnicities, political groups to entire nation states.

\section{Group-Based Conflicts and The Importance of Coordination}

The move from individual-level to group-based conflicts changes some features of conflict and keeps other constant. The basic features of the asymmetric war of attrition model still applies to humans and also when our conflicts are group-based: It is still adaptive to avoid fighting if loss is inevitable and, hence, a central feature of group-based conflicts is assessment of fighting ability. Yet, the factors that determine relative fighting ability change. In individual contests among non-human animals, the decisive feature for relative fighting ability is individual differences in physical strength and size. In group-based conflicts, a key feature of the group's fighting ability is the degree to which the group are able to solve the collective action problem of fighting. Important factors in this regard include 
number; the intensity of the members' willingness to sacrifice for the group; cohesion of the group; and the ability of the group to coordinate with each other on common projects.

In intergroup conflict, all else equal, the group which is better able to solve the collective action problems involved in force projection has greater fighting ability. Group-based conflicts are, essentially, arms races of cooperation (including recruitment) (Laustsen \& Petersen, 2015; Tooby \& Cosmides, 2010). This makes the collective action problem inherent in intergroup conflict different from other collective action problems. Normally, a collective action problem (e.g., a group hunt or raising a barn) requires the group to meet some absolute threshold of coordinated effort. In conflicts, however, this threshold is always a moving target, because the threshold is always relative to the other group.

Psychologically, this implies, first, that conflicts should be one of the contexts that most strongly activate psychological mechanisms for achieving within-group cooperation. Studies using experimental economics methods have produced significant evidence for this assertion (e..g, De Dreu et al., 2016). Second, when assessing relative fighting ability in intergroup conflicts, individuals need to pay attention to both their own group's degree of cooperation and the other group's degree of coordination. Experimental studies show that they do. Individuals spontaneously think of individual members of well-coordinated groups (specifically, groups that engage in synchronized marching) as physically stronger. Similarly, when individuals themselves are part of well-coordinated groups, they judge opponents as physically weaker (Fessler \& Holbrook, 2014).

In conflicts involving non-human animals false signals can surge in the initial stages of the conflict because these stages are signal-based rather than physical, i.e., contestants compete simply by signaling their formidability. The same applies to human group-based conflict. Accordingly, humans engaged in group-based conflict should signal to the target of their intimidation high numbers, high commitment, a determination to act together, and so on, regardless of the true 
state of affairs. (In the film Beau Geste, the dwindling defenders of an isolated fortress place the corpses of their comrades along the parapets with rifles sticking out to deceive the besiegers.) When group polarization starts, members of the rival factions should increase their mutual allegiance, emphasizing their unity; they should be motivated to adopt shared signals of coordination (e.g., shibboleths; gang signs; the proliferating cockades of different colors as factionalization proceeded in the French Revolution); and they should send out verbal signals of superior degrees of coordination (collective shouts; battle cries) (Hagen \& Bryant, 2003). Such signals are a central part of modern politics from the national level to the international level as seen in, for example, political rallies and military parades. As discussed regarding animal signals, there are strong limits to the extent to which false signals in these contexts are effective due to constraints grounded in efficient communication and vigilance. Below, we turn to situations in which these constraints are less limiting: that is, when falsehoods do not just spread between groups locked in conflict but also within each of the groups.

\section{Within-Group Coordination: Information and Followership}

Solving collective action problems entails solving at a minimum two separate problems. First, the group needs to solve problems of coordination, especially converging attention towards the same common project, and agree on its importance. Second, the group also needs to solve the collective motivation problem so that a sufficient number of people choose to give up the rival gains they accrue from their private actions and instead contribute enough effort in aggregate so that the common goal is achieved. This raises the problem of free-riding (Olson, 1965). Free-riders diminish the effort directly through non-participation, and secondarily through precipitating increasing unwillingness on the part of others to participate, because the human mind evolved to resist exploitation by limiting effort in the presence of free riders (Price, Cosmides \& Tooby 2002). Hence, we should expect that conflicts activate mechanisms for achieving both. Our focus here is on the coordination problem, 
where falsehoods are particularly important. Yet, while we focus on the coordination problem, we will also discuss the free-rider problem. Thus, we propose some of the features outlined below help solving both.

Coordination often involves concrete planning and a division of labor. The first step in coordination, however, is a matter of joint attention and convergent valuation. Coordination becomes possible when everyone attends to the same problem at the same time. First, this can happen because one problem is so salient that it intrudes on attention widely through the community (an enemy raids; the water overflows the riverbanks). Or, in more precise psychological vocabulary, because the cues associated with the problem fits into the psychological mechanisms that allocate attention. In such cases, joint attention emerges from the bottom up. But, secondly, it can also emerge from the top down through the explicit direction of leaders.

In coalition formation or consolidation processes both bottom-up and top-down coordination processes are at work. A political entrepreneur interested in enhancing coalitional formidability can facilitate both processes. The key way to foster bottom-up attention is via information-sharing where the information is strategically selected to (a) enhance the perception of opposing groups as threatening and (b) signal willingness and capability to meet the challenge (or opportunity) aggressively. The key way to enhance fighting ability via top-down attention is by following - i.e., promoting - leaders that themselves attend to intergroup conflicts and incentivize all group members to do the same.

Below, we assess how falsehoods are integral to processes of both coordination via information-sharing and the selection of conflict-oriented leaders. Specifically, we argue that (1) the sharing of false information can solve coordination problems; (2) statements of or agreement with false beliefs can effectively signal an individual members commitment to the group cause; and (3) that potential leaders can effectively demonstrate their potential for helping the group prevail in 
conflict by sharing false information. While it may seem a strong hypothesis to suggest the use of information in such strategic ways during group-based conflict is a reflection of biological adaptation, it should be noted that the use of other highly strategic forms of speech in interpersonal conflict (such as indirect speech) is indeed widely believed to reflect biological evolution (Pinker et al., 2008). As noted in the introduction, we here simply seek to deduce the structure of the underlying psychological mechanisms and leave it to future research to assess the totality of evidence for the proposed structures and their proposed biological underpinnings.

\section{Falsehoods as Tools for Coordination}

Horowitz's book, The Deadly Ethnic Riot, is a systematic review of a large range of studies about what happens before, during and after ethnic massacres across time and across the world. One of the central arguments is that the circulation of rumors, i.e., unverified or unverifiable information, plays a key role in the lead-up to all ethnic massacres. Horowitz explains why in the following way: "A rumor is a short-lived, unverified report, usually anonymous in its origin. No rumor that is disseminated widely enough to help precipitate collective violence can be understood as merely a chance falsehood or, as is commonly thought, a bit of misinformation that gains currency because official news channels have been remiss in putting out the truth. Concealed threats and outrages committed in secret figure prominently in pre-riot rumors. Since verification of such acts is difficult, they form the only way in which they facilitate violence. Rumors are structurally embedded in the riot situation, because they are satisfying and useful to rioters and their leaders, and so efforts to counter rumors may be misdirected. Rumor is likely to prevail over accurate information. (....) Rumor prevails because it orders and organizes action-in-process." (Horowitz, 2001).

Pre-riot rumors emphasize that the enemy group (a) devalues the welfare of the ingroup, (b) is powerful and (c) is about to attack. The way this is communicated is often in a series of rumors 
about horrific atrocities done by the outgroup towards the ingroup. Killing of children, poisoning of wells, raping of women are frequent themes. One of Horowitz's observations is that the more gruesome the atrocities contained in the rumors are the more horrific the following massacre events will be in terms of length, causalities and mutilations. To understand this, it is necessary to appreciate that Horowitz' argument is an argument about coordination, and he argues that the features of the rumors are carefully selected to serve this coordination or mobilization function. Thus, while it seem reasonable to hypothesize that gruesome rumors would motivate the receivers to flee from the enemy, their purpose is rather to instill a sense of urgency and direction: "We need to act now and this is what needs to be done." Essentially, the content of the pre-riot rumors provides a suggestion of the required force of joint violence that is being implicitly planned by the coordinating minds.

We have used the term "outrages" as the more general term for events (and information about) in which one or more members of one group injure the welfare of one or more members of another group (Tooby \& Cosmides, 2010). Psychologically, there are psychologically inflammatory (compared to a harm from one ingroup member to another) because the mind views it as an event that potentially advertises a status drop for the ingroup, thereby setting expectations for future interactions between members of the two groups. This is a collective threat which will adversely affect everyone in the group. If, as in the American South in 1900, a lynching is "accepted" mutely by blacks in the community (because protesting would have meant death), then that is a public advertisement of how blacks can be treated. If in contrast, a beating by police of a black driver in Los Angeles in 1992 is met with days of rioting, that is a signal that the members of the harmed coalition feel powerful enough — able to inflict enough costs - to repudiate the proposed mistreatment as a proposed equilibrium precedent. It is generalization (in the minds of observers) of the tolerated mistreatment from one or more members of a one coalition to one or more members of the other that makes group 
status a public good. This is why harms that cross group boundaries are hugely more psychologically salient than mistreatment of one ingroup member by another.

An outrage event serves as a coordination point whose immediate risk of status deflation motivates coalitional activation, which itself gives an opportunity to ride mass action to cohesion and expanded resources, dominance, and reputation. The argument is that the evolved design of the human mind contains adaptations designed to: 1) identify rivals (individuals or groups) whose status reduction, expulsion, or extinction would be advantageous to the individual; 2) probe for and identify audiences of potential allies who also benefit from reductive action towards your rivals; 3 ) be specially motivated to sift for, manufacture, interpret, remember, elaborate, "believe" and/or spread representations about the actions of the rival ("outrages") that depict the rival as harming members of your ingroup — or people potentially recruitable as allies. Groups nurture and curate their stories (true and false) of harms inflicted on them in the past, because these function as group resources that can be used to provoke ingroup solidarity and direct aggression exploitatively toward the outgroup.

To overcome the coordination problem, the mobilizing information inherent in outrages needs to flood the attentional system and direct attention away from other matters; it needs to direct the attention towards the outgroup; and it needs to signal extreme urgency at the "right" time. The time to strike is not always propitious, so minds should probe each other for signs of mutual receptivity. Those who have participated in demonstrations might have noticed periods of expectancy and the perception that something might be up; that is, a kind of waiting and low-level probing period; and then (either if enough mutually is sensed, or some external event occurs) the collapse from action potential to extreme action happens suddenly.

The evolved mind should be designed to select information on the basis of these dimensions (psychological convergence on the primacy of the group; joint outgroup attentional salience; readiness for sudden phase change to mutual mobilization). In contrast, as Horowitz 
emphasizes, the truth of the information involved in these rumors is largely irrelevant. Truth is not the salient dimension that the rioting mind selects its information on the basis of when it comes to conflict. From an adaptationist perspective, the point is not that the human mind is designed to actively spread misinformation. It is rather that the truth value of the claims that it propagates are not a relevant or motivating end in itself. At the same time, there is in fact a number of ways in which misinformation can be conducive to the ultimate aim of conflict-induced information sharing: mobilization.

First, reality is seldom as gruesome as fantasy. Hence, reality is seldomly sufficiently attention-grabbing. In a study arguing that false news stories travel faster and farther than true news, Vosoughi et al. (2018) not only demonstrate this but also demonstrate that this occurs because false news stories are often more novel and more emotional than true news. Essentially, it is their attentiongrabbing nature that facilitates the spread.

Second, from a mobilization perspective, inaccuracy of information is mainly a problem if it hinders the spread of the information. The dangers are two-fold: First, that attention can be driven away from the coordination signal in the information, if alternative information flows emerges that says that $\mathrm{X}, \mathrm{Y}$ and $\mathrm{Z}$ did not happen. Second, evidence does show that individuals suffer reputational consequences for sharing false information and, hence, there is reason to expect that information flows are disturbed if information is deemed false (Altay et al., 2019). As consequence, given that reality is seldomly juicy enough for massive mobilization, mobilization motivations should gravitate towards unverifiable information: Events occurring in secret, far away in time or space, behind closed doors etc. Unverifiability means that strong accuracy-oriented information flows have trouble gaining foothold in informational warfare. Unverifiability also means that sharers can engage in bet-hedging when they share the information, saying that "I don't know whether this is true but..." As will be clear, such bet-hedging should have a little to no limiting effect of the mobilizing potential of information. 
Third, inaccuracy of information is only a problem if the goal of processing the information is epistemic, i.e., evaluating truth claims about the world. What we argue is that when situations of group-based conflict have reached a certain intensity (specifically, when they have turned into zero-sum competition), information is primarily spread with the goal of coordination. Political science and recent psychology converge on the notion that people are not easily fooled (in the very specific sense of believing something that they are not predisposed to believe) (Mercier, 2020; Petersen, 2020). Part of the reason is that people, as other animals, have a large range of psychological defenses against manipulations, sometimes referred to as epistemic vigilance (Mercier, 2020). Yet, there is also evidence that these psychological defenses are selectively employed. When we receive information that is aligned with our coalitional interests and, in particular in situations of coalition conflict, the evidence suggests that these defenses are suspended (Druckman et al., 2013). The reason is that as a sense of zero-sum conflict crystalizes, information exchange shifts from being about assessing whether there is a conflict with the other group to being about whether the time for action is now. Zero-sum conflict is inherent in situations in which the existence of the other group itself poses a threat to your group. As such the question is only when to do something about it. The motivation for senders of mobilizing information is to say "I am ready," and the motivation of receivers is to assess "how many are ready?" The accuracy of the information is irrelevant here. It is the signal of the motivation inherent in the information that is key. And, returning to the first point, such signals can be better conveyed by exaggerating reality.

In sum, there are several reasons to believe that the human mind prioritizes false over true information in the context of group-conflict. This prioritization is not because the human mind is actively considering and evaluating the veracity of the information and choosing false over true. Rather, it is because that veracity is not the relevant dimension of evaluation; instead, the relevant dimension is mobilization-potential. And here false and extreme information is often more useful. 


\section{Falsehoods as Signals of Allegiance}

Coordination requires what is called "common knowledge." Common knowledge is a game theory assumption that is not objectively obtainable in the real world because it involves the processing of an infinite regress of "I know that you know that I know that you know that I know that..." (Thomas et al., 2014). Instead, evolution has collapsed this process and provides adaptations that yield its de facto equivalent: mental coordination (Tooby \& Cosmides, 2010). This results in the mental representation "we jointly know". In the context of group-based conflict, important questions are therefore (a) how to send signals that clearly reveal that you are in the know (i.e., mentally coordinated with others) and (b) what signals do you need to look for to know that others know? Again, it may seem a strong hypothesis to suggest that a psychology designed to answer questions of such strategic complexity evolved through processes of natural selection but, as reviewed by De Freitas et al. (2019), there is increasing evidence for exactly this hypothesis. Here, we focus on the structure of the potential evolved mechanisms underlying this complexity. As we will argue, these mechanisms should motivate people to send and scan for signals that have an incredible small probability of being signaled if all participants were not mentally coordinated.

Sending information that can easily be picked up outside the coalition is a bad signal because it does not reveal much about the sender's location within coalitions. It is in this light that we can understand some of the most extreme intergroup beliefs over human history. For example, a common theme in antisemitic propaganda is information that Jewish groups engage in ritualistic murder of babies and use the blood for baking traditional Jewish flatbread. From a signaling point of view such information is an effective signal. It is very unlikely a person would construct this information without being embedded in the relevant (here, antisemitic) information flows. It is a "hard-to-fake" signal of coalitional allegiance. Such signals not only generate common knowledge 
but also decrease concerns about free-riding in the ensuing coalitional action against the enemy, if the information is seen as a credible signal of commitment to the group cause.

Such signals are particular likely to be viewed as credible if they combine the demonstration of group-specific knowledge with the demonstration of group-exclusivity. Thus, social investments are zero-sum: What you invest in one-group cannot be invested in another. Groups that are motivated to be rivalrous about membership — which is the norm—-benefit by adopting beliefs that make you unacceptable to other groups. Specifically, the best beliefs for signaling allegiance to a group are beliefs that other groups will condemn (referred to by Mercier (2020) as a burning-bridges strategy). If this is part of the spontaneous psychology of coalitions, then one motivation for adopting a belief is simply that that an opposing group believes the opposite. This is especially true for domains where condemnation is likely, such as moral domains. In political science, for example, it has been repeatedly demonstrated that when individuals are informed of the positions of an opposing political party, they are more likely to take the opposite position (Leeper \& Slothuus, 2014).

Signals of group allegiance are not only important in the context of eruptions of group conflict. Thus, processes of group formation are so complex that they cannot wait until the enemy is in sight. For individuals living in a social ecology where conflict is likely, it could be beneficial to constantly keep signals of group commitment at sufficient levels of readiness. Furthermore, although the need for a coordinated group is particularly dire in group conflict, all collective action, including peaceful activities, requires at least some commitment from group members. Consequently, members should continuously scan for signals of group allegiance in order to assess the viability of impending or proposed group projects. Finally, when individual members of a group need to recruit help from the group, the help is contingent on signals that the receiving individual is willing to reciprocate in the future. Thus, individual members should continuously be motivated to send out signals of allegiance. 
Anyone of any identity can believe an evident truth; but only devoted ingroup members will endorse common claims that are not supported by evidence. This principle was used above to explain the circulation of falsehoods in the context of group-conflict. Yet, this is a general principle for signals of group allegiance, which can explain why tight-knit groups often develop beliefs for which there is little or no empirical evidence. Cults and fringe groups are notorious for maintaining odd beliefs, but here familiarity may fool us. Common religious beliefs are not just erroneous in minor ways; one of the markers of religious beliefs are their extravagant counterfactual nature. Take, for example, the Christian doctrine of Trinity, the notion that God is a at one at the same time one and three persons. There is no conceivable empirical evidence for this, and so no two people not connected by a common identity would happen to come up with such a strange and unlikely belief. Hence, logicor truth-defying beliefs can function as a hard-to-fake signal of immersion into a group. Because group-commitment is especially relevant in group-based conflicts, it is not surprising that psychologists are finding that these processes are heightened for individuals feeling threatened. Thus, a replicable finding is that feelings of threat motivate people to identify with radicalized groups, in part because the extreme belief systems of these groups offer greater possibilities of establishing a tight-knit group (so-called highly entitative groups) (Hogg, 2014).

In general, these psychological motivations to adopt unique, oppositional sets of representations in order to signal group commitment implies that belief systems can spin out of control, making people live in what are best characterized as illusions. It is important to note that the function of these beliefs is not epistemic: They do not serve as templates for how to navigate the world. They mainly exist as epiphenomena with a narrow signaling function. Accordingly, the illusions can have little negative consequences for the practical welfare of the individual and, hence, can be perpetually sustained. Because their function is to generate and signal group commitment, it is also plausible that they foremost emerge in domains where they can exist unhindered by the 
practical constraints of the physical world (e.g., in ideas about the afterlife). ${ }^{1}$ At the same time, this is not always the case, and many beliefs of extreme groups do spill-over over into domains of importance and generates negative feedback for their welfare (e.g., the rejection of blood transfusions among Jehovah's Witnesses). In general, we should expect that the greater the felt need for group commitment, the more costly beliefs people should be willing to adopt. Hence, we can see costly spill-over effects of commitment signals as indicators of the strength of the commitment: Only the truly devoted would adopt beliefs that involved significant costs.

\section{Falsehoods as Signals of Dominance}

Making statements that contain falsehoods might not just signal your motivation to promote the group cause in the context of conflict. Such statements might also signal your abilities to successfully lead the group to victory in the conflict. As noted, successful collective action involves solving both coordination problems and problems related to free-riding, and this is particularly important in intergroup conflict. Accordingly, evolutionary theories of followership have argued and demonstrated that human psychology in the face of conflict is designed to promote leaders who have the personal traits that enable them to solve such problems efficiently (Petersen \& Laustsen, 2020).

One such set of traits can be defined as dominance, i.e., the motivation and ability to induce compliance "through intimidation and coercion" (Cheng et al., 2013: 105). Research shows that people have heightened preferences for dominant leaders in contexts of intergroup conflict (Laustsen \& Petersen, 2020); that this effect of conflict is specific for individuals in leadership positions and does not reflect a general heightened preference for dominance across social roles

\footnotetext{
1 Above we noted that the use of blatantly false information could act as an obstacle to the spread of mobilizing information because countervailing information flows could emerge that questioned the information. This may be less important when information is used to signal membership to an already mobilized group where the common identity and goals would imply that there are less countervailing information flows. As consequence, in established groups increasingly fringe beliefs may emerge unhindered.
} 
(Laustsen \& Petersen, 2015); and, finally, results suggest that this reflects motivations to escalate aggression against the outgroup (Laustsen \& Petersen, 2017).

We spontaneously form impressions of dominance from many types of cues. Prior research has specifically looked at how people form impressions of the dominance of others through physical cues of masculinity and strength as well as behavioral cues (Petersen \& Laustsen, 2020). Importantly for the present purpose, individuals' endorsement of extreme and even false beliefs can in itself serve as signals of dominance.

Dominance can essentially be asserted by challenging others. As describe above, a function of beliefs is to serve as group-badges and, hence, one way to challenge others is simply to deny their beliefs. As a statement contradicts a larger number of people's beliefs, it serves as a better dominance signal. If this at the same time involves blatantly lying or holding on to beliefs that contradict obvious facts, the signal may be further enhanced. Statements of falsehoods can, in this sense, be a signal of dominance and, hence, increase the perceived appeal of the signaler as a leader in the face of intergroup conflict. In the context of contemporary politics, Hahl et al. (2018) hves provided some important evidence for this notion: Among individuals who are opposed to the established political system, blatant liars (i.e., statements that contradict common knowledge) are appealing because their behavior signals a disrespect for establishment norms such as truth-telling. As discussed by Hahl et al. (2018), this creates the paradox that politicians who obviously lie can appear more authentic.

It is relevant to distinguish between dominance-oriented motivations and abilities. Falsehoods serve as signals of dominance motivations. While such signals might in themselves suggest some ability, this implies that falsehoods primarily become relevant signals for, e.g., leader choice if there are parallel signals of dominance-oriented abilities. In a nut shell, in the face of conflict, people do not rally around every basement-dwelling, tinfoil-hat-wearing conspiracy theorist. 
But espousing such theories can serve as strong signals for individuals who are already powerful and, hence, induce individuals to rally around them.

\section{Conclusion}

There are tremendous adaptive benefits to the evolution of accurate perceptual systems, and, accordingly, we are able to estimate distance, catch a ball, build representations of the mental states of others and so forth without even thinking. Because humans are a social species, designed to live among con-specifics with non-overlapping interests, multiple of these systems are furthermore specifically designed to avoid being deceived by others.

Nonetheless, we sometimes entertain false representations. This can occur because of so-called mismatches. Natural selection is a slow and backward-looking process and, essentially, our brains are built for the physical and social demands of ancestral groups of hunters and gatherers. There are tremendous differences between the environment in which our decision-making apparatus evolved and the present environment in terms of social scale and technological complexity. A macroeconomy, for example, is a feature of large-scale societies with intense trading and, hence, it is not something our minds were designed to process. Accordingly, lay individuals have a large range of false ideas about how economies work (Boyer \& Petersen, 2018).

In this chapter, we have been interested in another cause of false representations: The entertainment of falsehood as a feature of human psychology rather than a bug. That is, selection pressures that entail that it is adaptive, under very specific circumstances, to transmit false representations and even, again under specific circumstances, to entertain these representations as true. Our focus has been on the selection pressures surrounding human conflict. Due to the groupbased nature of human conflict, the rapid facilitation of collective action has been key to the survival of our ancestors and, here, falsehoods can play a facilitating role. 
Specifically, we have been examining three ways in which falsehoods can serve adaptive functions. First, the spread of false information can facilitate the coordination of groups because such information more strongly can send the key signal that it is time to "go!". Second, statements containing false, illogical or unlikely representations can serve as enhanced signals of group commitment because such representations can be a signal of awareness of group-specific representations and exclusive commitment to the group. Third, statements containing blatant falsehoods can function as signals of dominance.

In sum, in order to understand the politics of falsehood, it is of key importance to understand that not all beliefs serve the function of representing the world accurately. Some beliefs are governed by evolved psychological mechanisms that exclusively have social functions. When contexts such as conflict intensifies the need for sociality, false beliefs are therefore likely to abound. Thus, it is no coincidence that truth is often argued to be the first casualty of war. But this is not just because of the existence of propaganda ministries and demagogic politicians. Rather, it is a reflection of the structure of the evolved psychology of human conflict.

\section{References}

Altay, S., Hacquin, A. S., \& Mercier, H. (2019). Sharing Fake News is Bad for Your Epistemic Reputation.

Arnott, G., \& Elwood, R. W. (2009). Assessment of fighting ability in animal contests. Animal Behaviour, 77(5), 991-1004.

Boyer, P., \& Petersen, M. B. (2018). Folk-economic beliefs: An evolutionary cognitive model. Behavioral and Brain Sciences, 41.

Buss, David (2015) The Handbook of Evolutionary Psychology, Vol 1 \& 2, 2nd Edition. New York: Wiley. 
Cheng, J. T., Tracy, J. L., Foulsham, T., Kingstone, A., \& Henrich, J. (2013). Two ways to the top: Evidence that dominance and prestige are distinct yet viable avenues to social rank and influence. Journal of personality and social psychology, 104(1), 103.

Dawkins, R., \& Krebs, J. R. (1978). Animal signals: information or manipulation. Behavioural ecology: An evolutionary approach, 2, 282-309.

De Dreu, C. K., Gross, J., Méder, Z., Giffin, M., Prochazkova, E., Krikeb, J., \& Columbus, S. (2016). In-group defense, out-group aggression, and coordination failures in intergroup conflict. Proceedings of the National Academy of Sciences, 113(38), 10524-10529.

De Freitas, J., Thomas, K., DeScioli, P., \& Pinker, S. (2019). Common knowledge, coordination, and strategic mentalizing in human social life. Proceedings of the National Academy of Sciences, 116(28), 13751-13758.

Diamond, J. M. (2013). The world until yesterday: What can we learn from traditional societies?. Penguin.

Druckman, J. N., Peterson, E., \& Slothuus, R. (2013). How elite partisan polarization affects public opinion formation. American Political Science Review, 57-79

Fessler, D. M., \& Holbrook, C. (2014). Marching into battle: synchronized walking diminishes the conceptualized formidability of an antagonist in men. Biology letters, 10(8), 20140592.

Gordin, Michael D. (2012). "How Lysenkoism Became Pseudoscience: Dobzhansky to Velikovsky". Journal of the History of Biology. 45 (3): 443-468.

Hagen, E. H., \& Bryant, G. A. (2003). Music and dance as a coalition signaling system. Human nature, 14(1), 21-51.

Hahl, O., Kim, M., \& Zuckerman Sivan, E. W. (2018). The authentic appeal of the lying demagogue: Proclaiming the deeper truth about political illegitimacy. American Sociological Review, 83(1), 1-33. 
Hogg, M. A. (2014). From uncertainty to extremism: Social categorization and identity processes. Current Directions in Psychological Science, 23(5), 338-342.

Horowitz, D. L. (2001). The deadly ethnic riot. Univ of California Press.

Huddy, L., \& Bankert, A. (2017). Political partisanship as a social identity. In Oxford research encyclopedia of politics.

Huntingford, F. A. (2013). Animal conflict. Springer Science \& Business Media.

Kurzban, R. (2012). Why everyone (else) is a hypocrite: Evolution and the modular mind. Princeton University Press.

Laustsen, L., \& Petersen, M. B. (2015). Does a competent leader make a good friend? Conflict, ideology and the psychologies of friendship and followership. Evolution and Human Behavior, 36(4), 286-293.

Laustsen, L., \& Petersen, M. B. (2017). Perceived conflict and leader dominance: Individual and contextual factors behind preferences for dominant leaders. Political Psychology, 38(6), 1083-1101.

Laustsen, L., \& Petersen, M. B. (2020). Online Tallies and the Context of Politics: How Online Tallies Make Dominant Candidates Appear Competent in Contexts of Conflict. American Journal of Political Science, 64(2), 240-255.

Leeper, T. J., \& Slothuus, R. (2014). Political parties, motivated reasoning, and public opinion formation. Political Psychology, 35, 129-156.

Mercier, H. (2020). Not born yesterday: The science of who we trust and what we believe. Princeton University Press.

Miller, J. M., Saunders, K. L., \& Farhart, C. E. (2016). Conspiracy endorsement as motivated reasoning: The moderating roles of political knowledge and trust. American Journal of Political Science, 60(4), 824-844. 
Muller, M. N., \& Wrangham, R. W. (2004). Dominance, aggression and testosterone in wild chimpanzees: a test of the 'challenge hypothesis'. Animal Behaviour, 67(1), 113-123.

Olson, M. (1965). The Logic of Collective Action: Public Goods and the Theory of Groups. Harvard University Press.

Osmundsen, M., \& Petersen, M.B. (2019). Danskernes tro på politiske konspirationsteorier. Om sammenhængen mellem politisk ideologi og konspirationsteorier i Danmark. Økonomi \& Politik, 92(3).

Pennycook, G., \& Rand, D. G. (2019). Lazy, not biased: Susceptibility to partisan fake news is better explained by lack of reasoning than by motivated reasoning. Cognition, 188, 39-50.

Petersen, M. B. (2015a). Evolutionary political psychology. The handbook of evolutionary psychology, 1-19.

Petersen, M. B. (2015b). Evolutionary political psychology: On the origin and structure of heuristics and biases in politics. Political Psychology, 36, 45-78.

Petersen, M. B. (2020). The Evolutionary Psychology of Mass Mobilization: How Disinformation and Demagogues Coordinate Rather Than Manipulate. Current Opinion in Psychology.

Petersen, M. B., \& Laustsen, L. (2020). Dominant leaders and the political psychology of followership. Current opinion in psychology, 33, 136-141.

Pietraszewski, D. Curry, O.S., Petersen, M.B., Cosmides, L. \& Tooby, J. (2015). Constituents of political cognition: Race, party politics, and the alliance detection system. Cognition, 140. 2439.

Pinker, S., Nowak, M. A., \& Lee, J. J. (2008). The logic of indirect speech. Proceedings of the National Academy of sciences, 105(3), 833-838.

Price, M. E., Cosmides, L. \& Tooby, J. (2002). Punitive sentiment as an anti-free rider psychological device. Evolution and Human Behavior, 23, 203-231. 
Richerson, P., Baldini, R., Bell, A. V., Demps, K., Frost, K., Hillis, V., ... \& Ross, C. (2016). Cultural group selection plays an essential role in explaining human cooperation: A sketch of the evidence. Behavioral and Brain Sciences, 39.

Sell, A., Tooby, J. \& Cosmides, L. (2009). Formidability and the logic of human anger. Proceedings of the National Academy of Sciences, 106(35) pp. 15073-15078.

Thomas, K. A., DeScioli, P., Haque, O. S., \& Pinker, S. (2014). The psychology of coordination and common knowledge. Journal of personality and social psychology, 107(4), 657.

Tomasello, M. (2014). The ultra-social animal. European journal of social psychology, 44(3), $187-$ 194.

Tooby J. and DeVore, I. (1987). The reconstruction of hominid behavioral evolution through strategic modeling. In Primate Models of Hominid Behavior, W. Kinzey (Ed.) New York: SUNY Press. Tooby, J. \& Cosmides, L. (1992). The psychological foundations of culture. In J. Barkow, L. Cosmides, \& J. Tooby (Eds.), The adapted mind: Evolutionary psychology and the generation of culture. New York: Oxford University Press.

Tooby, J. and Cosmides, L. (2020) Natural selection and the nature of communication. In The handbook of communication science and biology, Floyd; Kory and Weber, René (Eds.) New York: Routledge.

Tooby, J., \& Cosmides, L. (1992). The psychological foundations of culture. The adapted mind: Evolutionary psychology and the generation of culture, 19.

Tooby, J., and Cosmides, L. (2010). Groups in mind: the coalitional roots of war and morality, from Human Morality \& Sociality: Evolutionary \& Comparative Perspectives, Henrik Høgh-Olesen (Ed.), Palgrave MacMillan, New York, pp. 91-234. 
Tooby, J., Cosmides, L., \& Price, M. (2006). Cognitive adaptations for n-person exchange: The evolutionary roots of organizational behavior. Managerial and Decision Economics, 27, 103129.

Trivers, R. L. (1971). The evolution of reciprocal altruism. The Quarterly review of biology, 46(1), $35-57$.

Vosoughi, S., Roy, D., \& Aral, S. (2018). The spread of true and false news online. Science, 359(6380), 1146-1151.

Williams, G. C. (1966). Adaptation and natural selection: A critique of some current evolutionary thought (Vol. 75). Princeton university press. 